\title{
Smart Transportation System for Solving Urban Traffic Congestion
}

\author{
Godson S. Olusanya*, Monday O. Eze, Oluwaseun Ebiesuwa, Charles Okunbor
}

Department of Computer Science, School of Computing and Engineering Sciences, Babcock University, Ilishan-Remo, Ogun State PMB 4003, Nigeria

Corresponding Author Email: olusanyagodson@ rocketmail.com

https://doi.org/10.18280/rces.070302

Received: 13 August 2020

Accepted: 16 September 2020

\section{Keywords:}

mobility challenge, road emergency, road surveillance, city population, intelligent monitoring

\begin{abstract}
This paper, through critical literature review, has investigated the application of smart transportation system in handling traffic congestion with the aim of enhancing traffic flow in overcrowded cities. It has been discovered that the movement of people to urban areas in search of infrastructures and livelihood has drastically increased the population of people in such areas. This has resulted in traffic congestion, and created mobility challenges as people move from one place to another to carry out their daily activities. Many people have tried a number of traffic congestion avoidance techniques in order to meet-up with their daily appointments, one of which is moving at odd hours such as very early in the morning or late at night. This is far from being a reliable solution to the problem of traffic congestion. This research therefore, proposes an IT-based solution for traffic congestion through the concept of smart transportation systems also known as Intelligent Transport System (ITS). Its usage has given rise to the proliferation of smart systems in different urban sectors and it is projected to cover more areas of human endeavour because of its ability to proffer solutions through its adoption.
\end{abstract}

\section{INTRODUCTION}

Research has it that on a daily basis, people make decisions on where to live, and millions of people are involved in rural to urban migrations. It is projected that in the year 2030, $70 \%$ of the world's population will live in the city or at least within 5 kilometers to the city [1]. This increase, in the population of people living in the city, has resulted in an increase in the number of commuters moving into, within and outside of the city, on a daily basis. This therefore has resulted in the challenge of mobility (traffic congestion) as it concerns residents moving from one place to another.

The movement to and from places is becoming a thing dreaded by residents as they spend hours, that could have been gainfully utilized, in traffic [2]. Therefore, in an attempt to avoid this harrowing experience, residents have resorted to leaving home early in the morning and returning late at night. This pattern of movement however, results in an unhealthy lifestyle as the residents are not likely going to have a substantial number of hours to sleep.

Urban areas are faced with a lot of challenges due to the influx of migrants. One of such challenges is traffic congestion which has negative effects on the life span of people [3]. Since the migration to the urban areas is not likely to subside any time soon, it is therefore imperative for the urban areas to pay close attention to proactive management of the traffic flow. Such close attention should strive to deal with traffic congestions in the movement of residents into, within, and outside the urban areas, especially within. This underlines the importance of this current study which strives to proffer solutions to the traffic challenges of the city $[2,4,5]$. Thus, the adoption of the smart attributes which should give rise to a

\section{smart city.}

As smart-attribute is being adopted in cities, it is being harnessed to tackle the challenges of traffic congestion faced by crowded cities [6]. The adoption of the smart attributes in tackling the various challenges has brought about a proliferation of smart systems in different sectors of the city [7]. For example, tackling traffic congestion and helping to manage the functioning of the transportation sector has resulted in smart transportation system also known as Intelligent Transportation System (ITS) [8].

This paper therefore investigates the application of smart transportation system in the handling of traffic congestion so as to deliver a better traffic flow in the cities and help to improve the quality of life of residents.

The structure of the paper is given as follows: section 1 gives the introduction to the work, section 2 states the aim and objectives of the work, section 3 highlights the methodology adopted, section 4 gives a review of literature, section 5 outlines the expectations of a smart transportation system, section 6 presents a scenario based illustration and section 7 concludes the work.

\section{AIM AND OBJECTIVES}

The aim of this paper is to determine, through review, the applicability of smart transportation system in the handling of traffic congestion.

The specific objectives of the research are to:

(1) Review smart transportation system in literature

(2) Determine the applicability of smart transportation in handling traffic congestion 


\section{METHODOLOGY}

The review of smart transportation system will be done through the investigation of those related works which exist in literature. Efforts will be made to determine the applicability of the smart transportation system to traffic handling and monitoring.

\section{LITERATURE}

Urban areas are plagued with a lot of challenges which are traceable to its ever increasing residents jostling for the available insufficient resources and infrastructures. The desire to access infrastructures and maintain decent living conditions, especially in securing a sustainable means of livelihood has brought about a continuous migration of people from the rural to the urban locations [1].

This increasing population of people with its projection, not showing any sign of decline in the nearest future [1,9], is going to keep straining the resources and infrastructures that are available in the cities. The increasing demand for satisfaction by residents cuts across different sectors one of which is the transportation sector [9].

The transportation sector is seen as a sector which delivers a major component of cities' functionalities [8]. This component ensures mobility of residents to and from places of work, schools, places of worship and other social event locations. Despite the sector's delivery of mobility, it encounters challenges related to effectiveness and efficiency. The more pronounced challenge encountered is traffic congestion.

\subsection{Traffic congestion}

The commuting of cluster of people in the cities falling within the same period referred to as the peak periods has resulted in the traffic congestion commonly experienced. This experience takes away ample time which could have been used for more important engagements [10]. Commuting, in itself, is not the problem but the increasing number of commuters and the lack of proper management structure for their movement, within, into and from the city. This seems to be the bane of the transportation system of the urban areas.

There is therefore, a call for more structured and technologically inclined systems to handle the ever increasing population of the cities through smart systems [11]. It is expected that solving the issue of traffic congestion would impact lives more meaningfully, in the urban areas, hence the need for this critical review.

\subsection{Related system}

The research work of Yue et al. [12] introduced a smartphone application for traffic management and monitoring. The application is designed to perform three functions:

(1) Interaction with users through a mobile interface and display of real-time traffic condition.

(2) Prediction of seasonal traffic conditions based on historical data.

(3) Monitoring users' movements and locations for analysis and advising

The research work carried out by Saarika et al. [10] proposed a system to help minimize traffic congestion through intelligent parking aid, improve road safety, detect accident autonomously and delivery of critical information to commuters through intelligent signboards. The system is composed of a smart parking system which detects free and occupied parking spaces through on site sensors that communicate wirelessly with the system and a smart signboard which displays relevant information concerning route diversion and state of the road ahead to the commuters.

An intelligent transportation system was developed by Malygin and his colleagues for coordinated use of various types of transport means such as road, rail, sea and aviation [13]. The system proposed is an upgrade over existing ones which has been able to deliver an integrated management system for the supply chain with different transportation modes. The upgraded version called Multimodal Intelligent Transport System (MITS 3.0) makes use of information and telecommunication technology and artificial intelligence.

Anthopoulos and his colleague, Attour suggested carpooling as a way to help tackle traffic congestion in their research work [14]. Carpooling is a system which permits commuters moving in the same direction or wanting to deliver packages around similar locations to share a vehicle and bear the cost together. The rationale behind this is that limited vehicles will be on the roads when the commuters share vehicles.

Bawangaonwala alongside his colleagues carried out a review of different Intelligent Transportation Systems (ITS) in different cities of the world [15]. The conclusion of the review is that ITS is a promising solution for advanced traffic control and management.

A parallel transportation system which combines a real transportation system and a virtual or artificial one was developed in the study [16]. The real transportation system works in delivering current information concerning traffic in cities while the artificial transportation system works to describe an ideal situation and serve as a guide for the real transportation system to deliver the ideal expectation. The artificial transportation in general is able to describe, predict and prescribe based on analysis carried out using the information gotten from the real transportation system.

Toll collection being identified as a traffic congestion causative, especially during peak periods, motivated the work of the research [17]. The system they developed uses RFID tags for the collection of tolls on roads. The application came as a result of the quick-reading advantage of RFID readers over card readers. As a summary, the system is able to reduce the need for vehicles to come to a halt in order for the card readers to read the cards.

The research work of Yao and Liu [18] suggested a transportation system which integrates cities in a region, especially when there is a common infrastructure that is being accessed such as a sea port. The work considered the case study of Guangdong-Hong, Kong-Macao Greater Bay Area in proposing a modern integrated traffic network combining a multi-mode transportation.

The desire to reduce emission and tackle traffic congestion problems motivated the work done by Sierpiński et al. [19]. Their work is a proposition of an automated multi-storey garage, inclusion of bike renting services and car sharing system to help limit the need for commuters to always move around in their private vehicles. According to them, commuters can plan their movements in such a way that they can limit the use of their personal vehicles to certain areas while adopting the use of bikes and embracing car sharing in 
others.

Due consideration for the safety of pedestrians crossing the roads or using the walkways, motivated the work of Sharma and Battula [20] in the creation of a vehicle to everything system called FOOTREST. The incorporation of this system into the transportation system, according to them, will help make transportation seamless and intelligence driven as it concerns the relationship between vehicles and pedestrians.

The research work of Akter et al. [21] focused on public transportation operations especially in Bangladesh. They identified the inefficiency of manual/paper-based system of determining and paying passengers' fares; and the lack of accurate information on the arrival or departure of buses. This inefficiency made them develop an application with which passengers can book rides and track the location of buses while the payment of fares before entering the buses comes through the swiping of RFID cards; this invariably improves the operations of the transportation systems.

A system to help monitor roads was proposed by Bhogaraju and Korupalli [22]. The system uses inputs from deployed sensors and images from cameras mounted on roads to determine the condition and state of roads then alert roads users accordingly.

Managing road traffic in a dynamic and smart manner and the limitations of the conventional traffic light system birthed the work of Kumar et al. [23] in the proposition of Dynamic and Intelligent Traffic Light Control System (DITLCS). Rather than use fixed time duration to determine when to toggle among the colour of lights (Red, Yellow, Green), the system receives inputs such as traffic load and vehicle heterogeneity from sensors to determine how to control the traffic with due considerations for emergency situations.

\section{SMART TRANSPORTATION SYSTEM}

Proffering solutions to the challenge of traffic congestion is a major concern to the managements of cities. As smartattribute is being adopted in cities, it is therefore being harnessed to tackle this challenge. The adoption of smart attributes in the transportation sector results in smart transportation system [8].

The smart transportation system is seen as a system able to deliver a proper mobility function for the city and proffer solutions to the traffic problems experienced in the city [15].

The development and implementation of smart transportation systems in the cities is geared towards ensuring easy mobility for residents and effective and efficient movement of goods from one place to another.

Smart transportation systems are designed to go beyond mere monitoring and information gathering to include providing solutions to: traffic congestion and parking difficulties, increase in commuting time, public transport inadequacy, freight distribution ineffectiveness, improper dissemination of information regarding road situational reports, among others.

\subsection{Expected components of the smart transportation system}

(1) Smart Parking: A component of the smart transportation system which helps to identify free parking spaces in the vicinity of the driver, alerts the driver and also includes the price and direction to the free space location.
(2) Smart Road Surveillance: This provides on-road traffic cameras which will serve as video coverage devices for monitoring the roads and covering traffic conditions in the city. This system is capable of displaying real-time traffic conditions.

(3) Smart Traffic Monitoring, Management and Controlling: This system includes the control of traffic using traffic lights and a further inclusion of a smart system which will be able to make informed decisions on directing traffic based on the real-time state of the roads rather than a mechanical dependence on timing for traffic light control

(4) Smart Re-directing and Congestion Management: There are emergency situations, like accidents or construction works, which will call for traffic to be redirected to and re-routed through other roads. In order to make commuters avoid such occurrences on the roads and decongest the roads, this system re-routes traffic through alternative routes. Such new routes are then fed to the drivers.

(5) Smart Emergency Services: This system works in collaboration with other sub systems of the smart transportation system to deliver its functionality. The smart road surveillance, for instance, helps identify emergency situations on the road and pass on to this component for a determination of the form of emergency so as to autonomously alert emergency responders

(6) Smart Tolling: Toll stops on the roads contribute to traffic congestions, especially during peak periods. Smart tolling systems can help deal with this by taking away the stops from the roads and replacing them with online platforms for easy and seamless access.

(7) Dynamic Digital Board Display: As a board it is wirelessly connected to smart systems that feed it with updated weather information and environmental facts concerning the road ahead or any emergency situations on the road, including information like road diversions, re-routing among others.

(8) Command/Monitoring/Control Center: This serve as a monitoring center for oversight functionality. The monitoring ensures that immediate actions are taken to remedy situations requiring quick and urgent attention.

\subsection{Handling traffic congestion using smart transportation system}

Smart transportation system according to [11] is a key solution to handling traffic flow in cities. Smart transportation is projected as being able to manage traffic jams, thus leading to reduction of traffic time, reduction of accidents and the loss of lives through such mishaps, as well as conservation of fuel. The ability of Smart transportation systems to handle traffic congestion is a function of the capability of the components to deliver traffic solutions.

\section{APPLICABILITY OF SMART TRANSPORTATION SYSTEM IN HANDLING TRAFFIC CONGESTION}

The application of intelligence in the handling of traffic congestion has no other goal than to reduce it by way of removing any form of activity or occurrence (planned or unplanned) that can inhibit free flow of traffic 


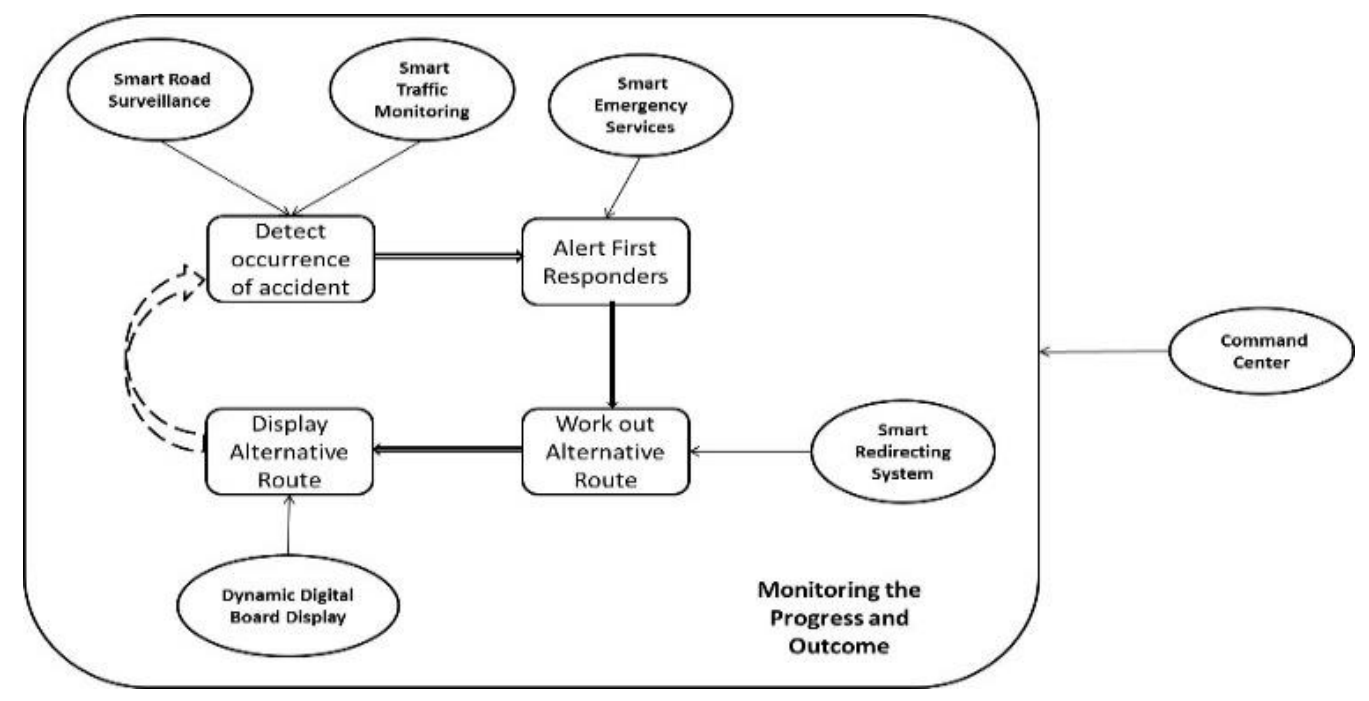

Figure 1. A typical operation of the smart transportation system

Determining applicability therefore, will follow the route of the investigation of the various components that make up the larger system. Some of the components earlier highlighted include: Smart Parking, Smart Road Surveillance, Smart Traffic Monitoring, Management and Controlling, Smart Redirecting and Congestion Management, Smart Emergency Services, Smart Tolling, Dynamic Digital Board Display and Command Center.

These highlighted components when deployed are expected to cover most of the planned and unplanned occurrences which result in traffic congestion. For example, accident occurrence is not planned but it is capable of inhibiting traffic flow thereby causing congestions. A combination of smart road surveillance, smart traffic monitoring, smart redirecting, smart emergency services, dynamic digital board display and command center is expected to effectively handle the occurrence.

The smart road surveillance and smart traffic monitoring system detect the occurrence of such accidents and alerts the first responders through the smart emergency services then an alternate route for commuters will be worked out through the smart redirecting system and displayed via the dynamic digital board display. The command center will then be involved in authorizing the operations autonomously and monitoring the progress and outcome. Figure 1 gives a pictorial explanation of this example.

\section{CONCLUSIONS}

The continuous influx of migrants into the urban areas from the rural areas increasingly strains the available resources in the cities, including passage ways. As the people come into the urban areas, they have to move around but the cluster of the persons moving at the same time causes traffic congestion. Tackling the problem of traffic congestion in the urban area requires smart and proactive approaches. An application of a smart approach is the adoption of smart transportation system in the management of traffic in the urban areas. Implementing smart transportation system as seen in literature is capable of reducing traffic congestion, improving the lifespan of residents, reducing parking difficulty, intelligently monitoring traffic flow and making appropriate interventions to forestall any form of traffic congestion build up that can impact upon the movement of residents.
Future research shall focus on an in-depth study and implementation of some of the components of smart transportation reviewed in this work.

\section{REFERENCES}

[1] Azgomi, H.F., Jamshidi, M. (2018). A brief survey on smart community and smart transportation. 30th International Conference on Tools with Artificial Intelligence, Volos, pp. 932-939. http://dx.doi.org/10.1109/ICTAI.2018.00144

[2] Talari, S., Shafie-Khah, M., Siano, P., Loia, V., Tommasetti, A., Catalao, J.P.S. (2017). A review of smart cities based on the internet of things concept. Energies, $10(4)$ : $1-23$. http://dx.doi.org/10.3390/en10040421

[3] Achmad, K.A., Nugroho, L.E., Djunaedi, A., Widyawan (2018). Smart city for development: Towards a conceptual framework. 4th International Conference on Science and Technology (ICST), Yogyakarta, pp. 1-6. http://dx.doi.org/10.1109/ICSTC.2018.8528677

[4] Albino, V., Berardi, U., Dangelico, R.M. (2015). Smart cities: Definitions, dimensions, performance, and initiatives. Journal of Urban Technology, 22(1): 3-21. http://dx.doi.org/10.1080/10630732.2014.942092

[5] Novotny, R., Kuchta, R., Kadlec, J. (2014). Smart city concept, applications and services. Journal of Telecommunications System and Management, 3(2): 18. http://dx.doi.org/10.4172/2167-0919.1000117

[6] Ahmed, F. (2017). Implementation of smart cities under IoT \& big data analytics. International Journal of Computer Science and Network Security, 17: 153-158.

[7] Jiang, L. (2015). Smart city, smart transportation: Recommendations of the logistics platform construction. International Conference on Intelligent Transportation, Big Data and Smart City, Halong Bay, pp. 729-732. http://dx.doi.org/10.1109/ICITBS.2015.184

[8] Pečar, M., Papa, G. (2017). Transportation problems and their potential solutions in smart cities. 2017 International Conference on Smart Systems and Technologies (SST), Osijek, pp. 195-199. http://dx.doi.org/10.1109/SST.2017.8188694

[9] Lenz, B., Heinrichs, D. (2017). What can we learn from 
smart urban mobility technologies? IEEE Pervasive Computing, 16(2): 84-86. http://dx.doi.org/10.1109/MPRV.2017.27

[10] Saarika, P.S, Sandhya, K., Sudha, T. (2017). Smart transportation system using IoT. International Conference on Smart Technology for Smart Nation, pp. 1104-1107. http://dx.doi.org/10.1109/SmartTechCon.2017.8358540

[11] Kosolsombat, S., Saraubon, K. (2018). A review of the prediction method for intelligent transport system. The 18th International Symposium on Communications and Information Technologies, Bangkok, pp. 237-240. http://dx.doi.org/10.1109/ISCIT.2018.8588015

[12] Yue, Y., Zhang, K., Jacobsen, H. (2013). Smart phone application for connected vehicles and smart transportation. Proceedings Demo \& Poster Track of ACM/IFIP/USENIX International Middleware Conference (MiddlewareDPT '13). Association for Computing Machinery, New York, NY, USA, pp. 1-2. https://doi.org/10.1145/2541614.2541627

[13] Malygin, I., Komashinsky, V., Tsyganov, V.V. (2017). International experience and multimodal intelligent transportation system of Russia. 2017 Tenth International Conference Management of Large-Scale System Development (MLSD), Moscow, pp. 1-5. http://dx.doi.org/10.1109/MLSD.2017.8109658

[14] Anthopoulos, L., Attour, A. (2018). Smart transportation applications' business models: A comparison. Proceedings and Companion Submissions of the 2018 Web Conference Companion, Lyon, France, pp. 927-928. http://dx.doi.org/10.1145/3184558.3191520

[15] Bawangaonwala, M., Wadhwa, D., Nandeshwar, U.V., Dhurate, S., Ramteke, S.P., Bante, P.N., Ansari, S. (2018). A review on development of intelligent transport system to compare with Nagpur transport system. International Journal of Computer Science and Mobile Computing, 7: 12-21.

[16] Zhu, F., Lv, Y., Chen, Y., Wang, X., Xiong, G., Wang, F. (2019). Parallel transportation systems: Toward IoTenabled smart urban traffic control and management. IEEE Transactions on Intelligent Transportation Systems,
1-9. http://dx.doi.org/10.1109/TITS.2019.2934991

[17] Fong, S.L., AbuBakar, A.A.A., Ahmed, F.Y.H., Jamal, A. (2019). Smart transportation system using RFID. ICSCA '19, Association for Computing Machinery, Penang, Malaysia, pp. 579-584. https://doi.org/10.1145/3316615.3316719

[18] Yao, S., Liu, L. (2019). Research on regional transportation network development strategies based on regional synergy: A case study of Guangdong-Hong, Kong-Macao Greater bay area. VTCA 2018, SIST 129, pp. 22-28. https://doi.org/10.1007/978-3-030-04582-1_3

[19] Sierpiński, G., Turoń, K., Pypno, C. (2019). Urban transport integration using automated garages in park and ride and car sharing systems - Preliminary study for the upper Silesian conurbation. TSTP 2018, AISC 844, pp. 218-228. https://doi.org/10.1007/978-3-319-99477-2 20

[20] Sharma, A., Battula, R.B. (2020). FOOTREST: Safety on roads through intelligent transport system. 2020 International Conference on Information Networking (ICOIN), Barcelona, Spain, pp. 818-820. http://dx.doi.org/10.1109/ICOIN48656.2020.9016473

[21] Akter, R., Khandaker, M.J.H., Ahmed, S., Mugdho, M.M., Haque, A.K.M.B. (2020). RFID based smart transportation system with android application. Proceedings of the Second International Conference on Innovative Mechanisms for Industry Applications (ICIMIA), pp. 614-619. http://dx.doi.org/10.1109/ICIMIA48430.2020.9074869

[22] Bhogaraju, S.D., Korupalli, V.R.K. (2020). Design of smart roads - a vision on Indian smart infrastructure development. 12th International Conference on Communication Systems \& Networks (COMSNETS), Bengaluru, India, pp. 773-778. http://dx.doi.org/10.1109/COMSNETS48256.2020.902 7404

[23] Kumar, N., Rahman, S.S., Dhakad, N. (2020). Fuzzy inference enabled deep reinforcement learning-based traffic light control for intelligent transportation system. IEEE Transactions on Intelligent Transportation Systems, 1-10. https://doi.org/10.1109/TITS.2020.2984033 